\title{
Erratum to: Disposal practices of unused and expired pharmaceuticals among general public in Kabul
}

\author{
Mohammad Bashaar ${ }^{1 *}$, Vijay Thawani ${ }^{2}$, Mohamed Azmi Hassali ${ }^{3}$ and Fahad Saleem ${ }^{4}$
}

\section{Erratum}

After publication of the original article [1] it was brought to our attention that author Mohammad Bashaar was incorrectly included as Mohammadk Bashaar. The correct spelling of the name is included in the author list of this erratum and updated in the original article.

\section{Author details \\ 'Health Policy Analyst, SMART Afghan International Trainings \& Consultancy, Kabul, Afghanistan. ${ }^{2}$ Professor of Pharmacology, People's College of Medical Sciences \& Research Centre, Bhanpur, Bhopal 462037, India. ${ }^{3}$ Professor of Social and Administrative Pharmacy, School of Pharmaceutical Sciences, Universiti Sains Malaysia, 11800 Minden, Penang, Malaysia. ${ }^{4}$ Faculty of \\ Pharmacy and Health Sciences, University of Baluchistan, Quetta, Pakistan.}

Received: 22 February 2017 Accepted: 22 February 2017

Published online: 06 March 2017

\section{References}

1. Bashaar M, et al. Disposal practices of unused and expired pharmaceuticals among general public in Kabul. BMC Public Health. 2017;17:45. doi:10.1186/s12889-016-3975-z. 